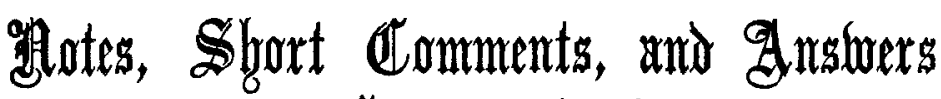 to Correspondents.}

\section{THE WORK OF THE METROPOLITAN ASYLUMS BOARD FOR THE MENTALLY DEFECTIVE.'}

By The Very Rev. Canon Sprankling, CHAIRMAN, METROPOLITAN ASYLUMS BOARD.

THe Metropolitan Asylums Board were required by an Order of the Local Government Board dated April 2nd, 1897, to provide accommodation for Poor-law children " who by reason of defect of intellect...... cannot properly be trained in association with chical interest to trace briefly the steps taken by the Board to deal with these children.

The Children's Committee (the Central Committee appointed by the Board to deal with cases under the Order of 1897) decided that it would be well to proceed experimentally by providing accommodation in ordinary dwelling houses scattered over the London area, each in touch with one of the special schools provided by the London County Council; at one time there were actually five such homes in existence, the first having been opened in January, 1899. The object was to provide the children with something as nearly akin as possible to the home life of a normal London child, and a house-mother was appointed for each home. The children attended the local special schools, and in some cases considerable improvement was effected. 'In 1906 provision was found necessary for continuance of control over the children after they reached the age of 16. The Bridge Training Home at Witham in Essex was opened as a working colony for male patients, while High Wood School, Brentwood, which is an institution built on the cottage home principle, had one of the groups of cottages, containing 60 beds, allocated for the accommodation of the elder feeble-minded girls. In 1911, however, the Board referred the whole question of systematic reclassification and treatment of the mentally defective cases, which fell within their sphere of work, to a special committee, who came to the conclusion that the experiment now under discussion had, in spite of all efforts, met with little success. The Committee formed the view that the permanent retention of the majority of the feeble-minded children was necessary in the interests of themselves and of the community, and that by this very fact the desired results could be obtained with as great efficiency in large colonies as in small scattered homes, and much more economically. Recommendations were submitted which led to the placing of all mentally defective persons in the Board's institutions, including the children already referred to (who were not certified under the Lunacy Acts) under the care of the Board's Asylums Committee.

\section{Provision of Certified Accommodation for the Mentally} Defective.

The passing of the Mental Deficiency Act, 1913, as it did not place on the Board any duties in regard to the provision of accommodation for mental defectives, did not immediately alter the policy which had been pursued in the past. In May, 1914, however, the Board were approached by the local authority for the metropolis (the London County Council) with a view to their providing certified accommodation under Section 37 of the Act for certain classes of the mentally defective. While the matter was under consideration war broke ont; the situation became so altered that the Board felt themselves unable to enter into an agreement such as was suggested. Two years later, however, an opportunity arose for the resumption of negotiations at the instance of the Board of Control and of the London County Council. Ultimately it was arranged that five of the Board's institutions should be certified for the treatment of cases under the Act of 1913, the whole to form a group known as the Metropolitan Asylums Board Certified Institution. Darenth Training Colony and Bridge Training Home were to receive improvablejuveniles, Leavesden and Caterham Mental Hospitals were to receive unimprovable adults from 16 years and upwards, and the Fountain Mental Hospital to receive idiot children. The Board made it perfectly clear that they could only undertake this work on special conditions. For instance, it was essential that they should have the absolute right to accept or reject any cases so that in no way should their normal work be jeopardised, and that, further, owing to the existence in their institutions side by side of two classes of certified cases, it would be impossible to follow all the prescribed forms required

Being the substance of a paper read on Nov. 26th, 1920, during the Conference on Mental Deficiency and Special Schools at Church House, Westminster. under the regulations laid down by the Board of Control. There were other stipulations such as a provision that patients might be transferred by the Board from one section of the certified institution to another without the consent of the Board of Control, and also that patients should be treated in precisely the same way as the Poorlaw cases received under the Lunacy Acts. The general idea was that the Board might be able to accept something up to 500 mental defectives from the London County Council area and from the Home Counties, with perhaps a few from provincial areas. In 1918, all arrangements having been made, the first cases were admitted.

To-day the Board have about 1000 mental defectives under their care, having thus exceeded by 100 per cent. the utmost promise they were able to hold out in 1917, but the available accommodation and the demand for it are now more or less equalised. Circumstances have rendered it necessary or desirable to depart in a measure from the original arrangements as to the classes of cases to be received at the different institutions. So far as Darenth is concerned, there has been, indeed, no change whatever, cases sent there being all of the trainable class, but it has been found that there are a goodly number of lower-grade cases who, while not prima facie number of lower-grade cases who, while not prima facie Darenth, may yet be considered as a separate class from the unimprovable adults it was originally intended should be sent to Leavesden and Caterham.

So impressed were the Board in 1919 with the pressure on the accommodation provided at the Fountain for the most deeply defective cases (it being understood that the Fountain was, in fact, the only institution of its class in the country) that they proceeded to make arrangements for the provision of accommodation for unimprovable children of both sexes at Leavesden Mental Hospital, in upper wards where only the less robust and physically vigorous could be accommodated; thus this provision only slightly relieved the demands on the Fountain.

Training of Patients in Simple Occupations.

Early this year, however, the congestion had again become acute in certain directions; medical superintendents of the various institutions were consulted and the opinion was expressed that there might be found at Darenth a number of cases which after reasonable trial were not "trainable" in the sense given to that word at Darenth, but still were not "unimprovable" in the sense applied to that word at Leavesden and Caterham. It was decided to examine the records of the male patients at Darenth with a view to transferring all those who fell in to this category to Caterham, there to be segregated as far as possible and employed in simple trades such as wood-cutting, land work, laundry work, \&c. The idea was that if these cases were found to be susceptible of a higher degree of training in any particular industry, steps would be taken to provide facilities for such training at Caterham. Further, the advantage of transferring cases which were not likely to benefit to the fullest extent from the special ised accommodation at Darenth was obvious, seeing that at that time there were about 180 cases of mental defectives awaiting admission to Darenth all classed as "trainable." Thus, the first considerable change in the original arrangements for the reception of mental defectives was made, a change which seems to mark a step forward in the classification of these cases. To-day a number of the patients thus transierred to Caterham from Darenth are engaged in industries (such as carpentry) with what is looked upon by the medical superintendent as a remarkable degree of success. The system adopted has been to start classes of three or four pupils in a very small way without any idea of "forcing the pace" or aiming at output. The patients are encouraged to play at their work in the first place. When they become interested and begin to understand how to use, for instance, a hammer and a nail, they are allowed to make some simple object which will be of use and which they know will be of use. There are classes also in mat-making and tailoring, but it will be understood that the whole scheme is, at the present time, in embryo, and that it is too soon to suggest any very reliable inferences as to its future possibilities. I should say in passing, however, that a similar scheme is being adopted on the female side at Caterham among the young women, who are being trained to do more than had hitherto been done there in the way of needlework, rug-making, and so on. Results of these experiments are being carefully watched. The next step was to make further use of the vacant male adult blocks at Caterham by transferring thither the elder boys at the Fountain who had reached the age of about 9 years, and were found more suitable for male than for female nursing. A block was therefore prepared at Caterham and all the boys were transferred last spring.

An interesting feature of this change was provided by the statement made to the Board by the responsible medical officers that it was hard to say that any child was quite "unimprovable," and that it was in fact more correct to say that nearly all the cases at the Fountain hitherto 
considered hopeless were trainable to a greater or lesser degree. It was decided in future to reserve the Fountain for unimprovable boys under the age of 9 , for unimprovable girls up to the age of 16 , and for children of both sexes whether stated to be "trainable" or not up to 7 years. The reason for this change was that it was felt that there was need for a testing institution at which children could be observed so that their capacity might be more or less accurately measured before they were sent to Darenth. Previous to this arrangement all -children of/ whatever age who were stated to be "trainable" had been admitted direct to Darenth, but it was found that so many were not really "trainable" in the Darenth sense that the accommodation there became as it were choked with cases which were not suitable, and which could not benefit by the specialised arrangements provided. On the other hand, the children admițted to the Fountain as unimprovable had, in some cases at any rate, been found to be so far superior to the original estimate of their capacity as to be suited for Darenth. At present, therefore, all children under 7 are admitted to the Fountain, where they are carefully watched, and after a longer or shorter period the medical superintendent of that institution consults the medical superintendent of Darenth with a view to the admission to the latter colony of all those whom experience has shown are "trainable."

Christmas Toys for Sick Children.

This procedure of selection is, as a matter of fact, merely carrying into the working of the Mental Deficiency Act the scheme which has worked well in connexion with Lunacy Act cases. So far no use was made of Bridge Training Home under the Mental Deficiency Act. Cases there are all uncertified. Apart from school training at Darenth a very large number of industries are carried on; and the Metropolitan Asylums Board actually relies to a considerable extent for the toys provided every Christmas for the children in their hospitals upon the workshops at Darenth which make these toys from waste materials of all kinds. Leavesden Mental Hospital has been as far as possible turned into an infirmary for the harmless imbecile classes and to a large extent its inmates are Lunacy Act cases. The mentally defective children housed there are practically all paralysed or helpless, and, while everything possible is done for them, their infirmities are so many and so overwhelming that it is hardly possible to give them any instruction or training. But these cases are not to be taken as disproving the view that few cases can truly be spoken of as " unimprovable."

At the Fountain Mental Hospital the very lowest grade of idiot children is provided for, the common types admitted being the helpless, paralysed, and epileptic. It became evident soon after the hospital was opened that as many of these children were trained to feed and dress themselves, and in other ways become clean and even tidy and useful, some higher form of training might be attempted. To this end a school was started in 1917, a suitable teachernurse being selected to take charge of the children. She started by teaching them how to play, and gradually advanced them through elementary kindergarten work, musical drill, and singing with action songs and dancing, to doll-making, mat-making, and the dressing of dolls. This simple instruction may not appear to mean much, but in practice it is found to be economical in many ways, and, above all, the lives of these unfortunate children are made much brighter and happier. Every care is taken to select suitable nurses who are specially interested in children, and over them are fully trained sisters who work in conjunction with the matron and her assistant. After the ohildren have been to school for a certain period they are subjected to special tests periodically by the medical officers with a view to selecting the best for further intensive training at Darenth.

No one who sees the children as they are on admission can fail to be struck with the remarkable change achieved in most instances after a comparatively short period. The patience and care lavished on these afficted atoms can hardly be appreciated except by those who watch the work of the institution constantly.

I need scarcely say, in conclusion, that the Board are well aware of the splendid work done under Section 37 of the Mental Deficiency Act, by boards of guardians and combinations of boards of guardians at Monyhull Colony and elsewhere.

\section{EXPERIMENTAL GIGANTISM BY FEEDING WITH} PITUITARY GLAND.

WHEN growth continues beyond the normal size of the species the condition is known as gigantism. Clinically, evidence points to the conclusion that at least one form of gigantism is due to over-function of the pituitary gland. Attempts, however, to produce gigantism by feeding with pituitary have not hitherto been successful. E. Uhlenhuth,
of the Rockefeller Institute. has continued his researches and has now succeeded in producing experimental gigantism. His experiments were made on salamanders, and the experi ments showed that it is the anterior lobe alone of the gland which possesses the ability of maintaining growth after the normal size of the species is reached. The function of the posterior lobe is still unknown, since it is the intermediate part which supplies the extracts which excite unstriated muscle, produce diuresis, and raise blood pressure. The effect of the anterior lobe diet depends on the developmental stage of the salamander. Larvæ do not respond to it; the growth-promoting effect of the gland commences only after metamorphosis has taken place. Specimens of Amblyostoma opacum have been kept and measured for several years. After the first year the animals grow very little. The largest control animal in one group measured $115 \mathrm{~mm}$., while the largest hypophysis-fed animal measured $138 \mathrm{~mm}$. In another example the normal typical animal, 3 years old, measured $111.5 \mathrm{~mm}$., and the corre sponding control $131 \mathrm{~mm}$. at 2 years of age. The feeding was begun after the animal was 1 year old. Similar result were obtained on the species $A$ tigrinum. Every single animal of this species fed on the anterior lobe outgrew all the controls and other normal animals raised in the laboratory. If the animals were fed on the posterior lobe grow th was not only not stimulated, but even greatly retarded. Feeding with the anterior lobe causes: (1) a very marked acceleration of growth ; and (2) a continuation of growth beyond the specific size of the species, resulting thus in hypophysis or pituitary gigantism. It is impossible to renew growth by feeding with large quantities of normal food after growth has practically come to a standstill. The continua. tion of growth beyond the normal size of the species is not due to an increased amount of food, and it would seem that at a stage where growth ceases or is greatly diminished under normal conditions cell proliferation can be actually enforced by the specific growth-promoting substance contained in the anterior lobe of the hypophysis.

\section{THE BOLSHEVIST UNIVERSITY OF SARATOFF.}

AT Saratoff, on the Volga, has been established the first free scholastic and socialistic University, of the ordinances of which the Italian journal, Patologica (xiii., 291, Jan. 1st, $1921,3)$ reproduces the salient points. The aims of the University are apparently (1) to give the proletariat a com munistic conception of the world based on rigorously scientific data; $(2)$ to initiate the proletariat at the earliest possible moment into all the most recent discoveries of science by inducing it to seek ever new scientific paths (3) to explain to the masses the intimate connexion between the so-called exact sciences and practical life; (4) to excite in them not only a burning zeal for knowledge but for action also; (5) to direct them towards creative activity on a scientific basis; (6) to guide, train, and attract towards activity creative of social reconstruction the more capable proletarian elements; (7) to create institutions qualified to develop in the citizens aspirations towards self-culture.

Systematic and special lectures have been organised, together with work in laboratories, scientific departments libraries and museums, and scientific excursions will be undertaken. All citizens of both sexes over 16 years of age who can read and write may attend the University, and the students are divided into groups in accordance with $(a)$ the state of their preparatory work and mental development (b) their predilection for one or other branch of science c) their reference to some particular psychological type as determined by the application of tests

The syllabus of instruction comprises $(1)$ the Universe (Cosmology), (2) Man (Anthropology), and (3) Human Society Social Sciences). Since the aim of the University is not only the development of the intellect but also the develop ment of character, the fundamental principle of th socialistic University is the self-education of the students To this end the University has organised a series of lecture on the development of the will power by auto-analysis (systematic self-observation) and by some degree of practical instruction applied by the student to himself. To make the teaching more homogeneous and to link up all the subject taught, a chair of Methodology (the first in an institution of this type) has been created for the purpose of unifying the separate lectures and making them conform to the fundamental programme of the University-the attainment of a vast communistic interpretation of the Universe. The course will extend over two or three years and the lectures will be given during three hours on three or five evenings every week. In association with the University are libraries, laboratories, museums, excursion and information depart. ments and means for liaison with other similar organisations. When every citizen possesses not only general knowledge but also a scientific grounding, is able to think and speak, to make scientific generalisations and researches, to think for himself and to illumine scientific concepts with the facts of daily life, the world should be a very different place. 